\title{
Infraestructura del abasto de carne a la ciudad de Córdoba: los Corrales (1783-1810)
}

Ana María Martínez de Sánchez Córdoba, Argentina

El abasto de frutas, verduras y otros bastimentos no demandó, en general, un esfuerzo especial de infraestructura para su expendio. En la plaza principal o a través de las regatonas, se comercializaron los productos de diario consumo. Caso aparte presentó el abasto de carne, por dos motivos principales: la necesidad de controlar las reses que se introducian y vendian-tanto por sus condiciones sanitarias como para evitar la práctica del abigeato- y la necesidad de aumentar los ingresos de propios de la ciudad, mediante el cobro de un impuesto.

El emplazamiento de los corrales y el matadero fue una de las preocupaciones fundamentales del gobernador intendente Sobre Monte, quien organizó una adecuada infraestructura para el abastecimiento y sus controles. Entre ellos se creó el cargo de mayordomo de corrales; quien debía llevar cuidadosa cuenta del Ramo de corrales, que ingresaba a la cuenta de propios de la ciudad.

\section{Introducción}

El conocimiento de cómo se formaron y funcionaron los Corrales y el Matadero de la ciudad de Córdoba, a fines del siglo XVIII, nos permite valorar la importancia que ellos tuvieron dentro de la infraestructura general de abasto a la población.

El Cabildo, eje sobre el que giró este requerimiento, nos da a conocer, a través de las actividades del fiel ejecutor, los regidores de plaza y, especialmente, el procurador de ciudad, las necesidades y proyectos que encauzaron y determinaron el sistema. Siempre con intervención del gobernador intendente, se legislo, se fijaron tarifas y condiciones de faenamiento.

Este trabajo pretende aportar elementos que, unidos a otros temas como el funcionamiento de la plaza, los abastecedores o las carretillas, puedan conformar un panorama de lo que fue el abas- 
to de carne a la ciudad durante este período de la gobernación-intendencia.

\section{Los corrales}

\section{El solar}

Inmediato al acto de fundación se trazaba el plano de la nueva ciudad y se señalaban los solares destinados a sus principales actividades. La plaza fue el lugar de reunión de los vendedores que proporcionaban diversos abastos a los habitantes de Córdoba.

El abasto de came, tantas veces mencionado como el alimento primordial de la población - especialmente de la gente pobretambién preocupó al Cabildo quien trató, en reiteradas oportunidades, que se destinaran solares para la construcción de corrales. Ya en la traza hecha por Lorenzo Suárez de Figueroa, teniente general del gobernador Gonzalo de Abreu, en 11 de julio de 1577, aparecen señalados los solares para Matadero y Corral de Concejo, ${ }^{1}$ pero a fines del siglo XVI esos terrenos aún permanecían baldíos. ${ }^{2}$

En 1625, el mismo predio aparece como Matadero y Corral y su situación continuaba siendo baldía, igual que en 1650 y $1675 .^{3}$ Estos terrenos estaban situados dentro de la traza de la ciudad, en las primeras setenta cuadras que se adjudicaron y fueron poblándose a partir de la fundación, a las que rodeaban las tierras comunales que la legislación indiana distinguió en ejidos, dehesas y propios. ${ }^{4}$

1 Corresponde a la ubicación actual de calle Lima, entre Salta y Santiago del Estero, vecino al río que corría - en dos brazos- por su antiguo cauce. Ver lám. 1.

2 Luque Colombres, Carlos: Origenes históricos de la propiedad urbana en Córdoba (siglos XVI y XVII), Córdoba, 1980, pág. 99.

3 Ibidem. Ver los planos correspondientes a cada capítulo.

4 Los ejidos eran terrenos, fuera de la traza, que se arrendaban mediante el pago de un censo; las dehesas: extensiones ubicadas a las afueras que servían de paseo público, donde se plantaban alamedas y pastaban los animales de cuadra y corral; los propios eran terrenos destinados a producir renta como base del presupuesto concejil. Baldíos se designaban los solares dentro de la traza que estaban desocupados y sin construcción. Grenón, Pedro, S.J.: El libro de egidos, Córdoba, 1931. Ots Capdequí, José María: España en América. El régimen de tierras en la época colonial, México, 1959. 
Las dehesas quien más las aprovechaba era el obligado al abasto de carne o carnicero, porque allí mantenía el hato de consumo, y los arrieros, que soltaban allí sus reses. ${ }^{5}$

En el Acta de Cabildo de 27 de noviembre de 1648, al tratarse el modo de conservar la acequia, se ordenó que se retiraran los ganados que la estropeaban al pastar y se acordó que el que se recogiere:

“...se traiga a corral de Concexo y no se suelte hasta que aya pagado el dueño dellos a dos reales por cabeza del ganado mayor y por el menor un real por dos cabezas..." 6

Matías Suárez, encargado del cuidado de la compuerta de la toma, podría recoger dichos ganados y llevarlos al corral. No sabemos si el Cabildo se refiere al designado en la traza o a alguno que funcionaba en otro lado de la ciudad. Lo que sí podemos afirmar es que para esta época había un lugar, teóricamente cercado, que cumplía con la función de encerrar el ganado.

Es factible que tal sitio haya existido a lo largo del siglo XVIII ya que al exponer su parecer sobre el modo de construir los corrales de 1786, el síndico procurador dice al Cabildo:

“...sin que sirva de obstaculo el perjuicio que se quiera suponer se irroga a los que en la actualidad se tienen los relacionados corrales, que por ser su fábrica de palos es de poco momento..." 7

Es decir que, durante la segunda mitad del siglo XVII y la mayor parte del siguiente, existieron corrales pero no matadero.

En los primeros años de Córdoba hubo obligados, personas que arrendaban el abasto de carne por un año, o a veces dos, a precio y condiciones estipuladas en la subasta. Faenaban en sus casas, y de acuerdo a las quejas que presentaba el vecindario al Cabildo, frecuentemente lo hacían en lugares públicos, causándoles serios in-

5 Bayle, Constantino: Los Cabildos seculares en la América española, Madrid, 1952, pág. 87. También los propios fueron utilizados por los obligados.

6 Archivo Municipal de Córdoba (en adelante AMC), Actas Capitulares, Libro noveno, Córdoba, 1952, pág. 578.

7 Ibídem, Libro trigésimo séptimo, fol. 186v. El subrayado me pertenece. 
convenientes. El obligado no tuvo entre las condiciones impuestas, la de faenar en lugar determinado. ${ }^{8}$

La multiplicación del ganado hizo que, en las regiones donde esto sucedía, el abasto de carne no fuera una tarea redituable y por ello fue desapareciendo el oficio, reservándose para las zonas más áridas donde la carne tenía mayor valor. ${ }^{9}$

Bayle afirma que, de toda América, donde más barata se cotizó la carne fue en el Río de la Plata; por ello en el período que estudiamos y rastreado el siglo XVIII, hallamos obligado sólo en circunstancias de excepción. ${ }^{10}$ Desde mediados del siglo XVII ya había dificultades y falta de postores para la subasta del abasto de came. "l

Como el suministro lo hacía un número variable de hacendados, según las épocas de escasez o abundancia, surgió la necesidad de circunscribir la matanza a una parte de la ciudad y construir un matadero. La primera mención que hemos hallado sobre la construcción de un corral y matadero data de 1668 . El acuerdo capitular de 13 de enero dice:

“...en este Cabildo se confirió el que se aga un Corral con su trascoral que sirba de carneseria y que no se pueda matar el abasto de la carne ni despender en otra parte, $y$ asi mesmo que qualquier tropa de mulas u otro ganado que ubiere de pasar se ensiere en el y pague un peso por cada noche y que no se pueda enserrar en otra parte pena del que les diere corral de quatro pesos aplicados para camara de su magestad y la otra para gastos de obras publicas y el sitio donde se a de aser el dicho corral señalaron el solar que esta entre el rio y edifisios del conbento que se enpeso aser de la señora Santa Clara y se comete al capitan Don Juan de Garay, alcalde ordinario." 12

8 Luque Colombres, Orígenes históricos..., pág. 410.

9 Bayle, Los Cabildos seculares..., págs. 473 y ss. Marca la rápida evolución de la ganadería en toda América y hace especial mención al abasto de carne. También aborda el tema Carlos M. Stomi: Acerca de la regulación jurídica del abasto de carne a las ciudades. Siglo XVIII, en "Revista de Historia del Derecho", n. ${ }^{\circ}$ 18, Buenos Aires, 1990, pág. 443. 302.

10 AMC, Actas Capitulares, Libro trigésimo, fols. 183, 247 a 249, 252, 283, 291 y

11 Ibídem, Libro noveno, págs. 301, 410 y 700. Libro décimo, Córdoba, 1953, págs. 58, 59, 253 y 326. Libro undécimo, Córdoba, 1954, págs. 306, 437 y 438.

12 Ibídem, Libro undécimo, pág. 302. Ver lám. 1. 
De acuerdo al estudio hecho sobre la propiedad urbana en Córdoba, este proyecto no llegó a concretarse.

La segunda mención de hacer matadero en la ciudad aparece en 1686, cuando el procurador general de la ciudad, capitán Ignacio de Ledesma, reclamaba su construcción en el lugar señalado en la traza. El Cabildo no accedió a aprobar su proyecto pero se arbitró que:

“...atendiendo a que es conveniente el que dicha obra se haga y para el mayor augmento de dichos propios asignamos el diez por ciento de todas las vacas cimarronas que se vaquearen de esta ciudad para que su procedido entre en poder del maiordomo de la ciudad y lo tenga de manifiesto para en habiendo la concurrente cantidad se haga dicho matadero..."13

En 1755, los primitivos solares designados para Matadero y Corral aún aparecen despoblados ${ }^{14} \mathrm{y}$ en 1768 fueron cedidos en enfiteusis a don Manuel de Castro. ${ }^{15}$

En el plano de la ciudad reconstruido por el padre Pedro Grenón en base a las menciones del censo de 1778, aparece como calle del Matadero la que rodeaba a la traza por el norte, hoy calle Santa Rosa-Lima. ${ }^{16}$

Coinciden por lo tanto los datos en ubicar el primer solar destinado a Matadero en esa parte de la ciudad aunque nunca se haya efectuado allí una construcción ad-hoc.

En los años siguientes al de la construcción mandada por Sobre Monte -que más adelante nos ocupará- y al traslado realizado en 1805, aparecen, en las Actas Capitulares y en los expedientes de las Escribanías, numerosas menciones de proximidad o linde con

13 Archivo Histórico de la Provincia de Córdoba (en adelante AHPC), Escribanía I, leg. 161, exp. 5, fol. 50r. de fecha 21 de octubre de 1686 .

14 AHPC, Escribanía 2; leg. 25, exp. 8. 1755. Luque Colombres, Orígenes históricos..., pág. 412 .

15 Ibídem. En 1809 fue comisionado por el Ilustre Cabildo para el reconocimiento de los ejidos y la traza y confección de un plano, Francisco Patiño y González. Según la explicación que él incluye sobre la cuadra destinada primitivamente a Matadero y Corral, la mitad era propia por merced hecha al ya finado don Manuel de Castro y de la otra mitad pagaba censo a la ciudad don Clemente Castro.

16 Grenón, Pedro, S.J.: Municipalidad de Córdoba, Córdoba, 1949. Ver lám. 2. 
los terrenos de los "corrales viejos". Al ubicar la situación de los terrenos de los solicitantes hemos podido delimitar el lugar donde fueron construídos en 1786.

El primer matadero se levantó más al norte de los solares destinados primitivamente, en el bajo del río, que para fines del siglo XVIII había unificado su cauce. En los primeros tiempos de la ciudad corría en el límite de la hoy calle Santa Rosa un brazo del río dejando, entre éste y el cauce propiamente dicho, una isla.

Corrobora nuestra ubicación saber que Juan González solicitó un pedazo de terreno en los corrales viejos, el 20 de septiembre de 1805. ${ }^{17}$ En el plano confeccionado por Francisco Patiño en 1809 ese terreno adjudicado a González aparece con el $n .{ }^{\circ} 101$ de ejidos. ${ }^{18}$

En una lista de los ejidos de la ciudad dados en enfiteusis en septiembre de 1854, aparecen los terrenos 101, 103, 122 y 123, dados a don José Brizuela —en la extensión de dos cuadras de 50 varas de naciente a poniente - "entre los brazos del Río, hasta dar con su lecho principal al N". ${ }^{19}$ No cabe duda, entonces, que los corrales viejos se construyeron en los terrenos ribereños, barrosos, dejados por el río al norte de la ciudad, siempre expuestos a las avenidas del mismo.

Los corrales nuevos - 1805- aparecen bien delimitados en el plano de Patiño, en la parte sudeste. La larga disputa originada por la adjudicación de terrenos de ejidos en la zona de la nueva construcción, entre Vicente Antonio Bedoya, José Ignacio de Urizar, Francisco Inocente Gache, Agustín Arraigada e Ignacio Peiteado, ${ }^{20}$ nos permitió corroborar la ubicación que le asignó Patiño en 1809.

En agosto de 1805, Pedro Rodríguez Miguel solicitó un pedazo de terreno de ejidos, inmediato a los "corrales nuevos". El Cabildo no hizo lugar a la petición, ni a otras similares que se presentaron, ya que consideraron los terrenos vecinos a los corrales para uso de los matanceros y para la frecuente mansión de las tropas de carre-

17 AMC, Actas Capitulares, Libro cuadragésimo segundo, fol. 286v. Ver lám. 3.

18 Ibídem, Libro de la Traza de la ciudad de Córdoba y sus egidos. Año 1809.

19 Ibídem, fol'. 10r.

20 Grenón: El libro de egidos..., págs. 118 y ss. 
tas. Se les permitió tener allí algún ganado sin otorgarles derechos sobre el terreno, del que no podía disponer el Ilustre Cuerpo por estar cedido en beneficio a la ciudad. ${ }^{21}$

Los terrenos en cuestión -que solicitaban los linderos a ellos invocando, a veces, el derecho a "acrecer" ${ }^{22}$ - eran los dejados por la retirada del río. Si se otorgaban entorpecerían la entrada y salida de arrias y carretas por coincidir con el camino del Pucará, que era la entrada de las procedentes de Buenos Aires y Santa Fe. ${ }^{23}$

La ubicación de los corrales nuevos ha sido fácil de lograr por las numerosas referencias sobre su cercanía a terrenos claramente identificados. Por ejemplo a la cancha de bochas de Agustín de Arraigada, donde los peones afectados a la matanza se jugaban, en algunas ocasiones, hasta el producto de las reses de sus patrones. ${ }^{24}$

A pesar de las representaciones de los vecinos y facultativos que consideraron ese lugar el más apropiado para el nuevo emplazamiento, hacia 1811 don José Roque Savid, procurador general de la ciudad, presentó un escrito en el que hacía presente el peligro en que se hallaban los corrales a causa de las continuas y abundantes crecientes del río y para prevenirlo solicitó la traslación de ellos a otros terrenos contiguos al Pucará, que nosotros ubicamos en la parte alta de él ya que en 1805 se habían construído en la baja. ${ }^{25} \mathrm{~Pa}$ ralelo al arreglo de los corrales se pedía la reparación del camino de entrada y salida en el punto del Pucará. Lo único que se hizo fue arreglar el río en esa altura.

Otro nuevo matadero se construyó en 1863 en el lugar que hoy ocupa la estación del ferrocarril General Mitre, el que debió destinarse a estación en 1869, precisamente por hacerse entonces el tendido de líneas férreas. ${ }^{26}$

21 AMC, Actas Capitulares, Libro Cuadragésimo segundo, fol. 267v.

22 Derecho de acrecer: cuando el río corre su madre, esos terrenos quedan para los dueños de las heredades contiguas. AHPC, Escribanía 4, 1811, leg. 41, exp. 4.

23 Ibídem, Escribanía 1, 1809, leg. 436, exp. 6.

24 AMC, Actas Capitulares, Libro cuadragésimo tercero, Córdoba, 1969, págs. 213 y 267. AHPC, Gobierno, año 1807, Caja 29, carp. 4, fol. 292.

25 Ibídem, Libro Cuadragésimo sexto, Córdoba, 1960, pág. 265.

26 Poca, Guillermo: La Municipalidad de la ciudad de Córdoba (1857-1870), Tesis de Licenciatura, inédita, Facultad de Filosofía y Humanidades, Universidad Nacional de Córdoba, 1978, pág. 105. 
En 1870 se instaló en San Vicente el Matadero de ganado, en la orilla este del río Primero y los respectivos corrales y playas para la matanza de reses. ${ }^{27}$ Este nuevo emplazamiento aparece identificado con el número 30 en el plano delineado y grabado por Miguel Potel Junot en 1878. ${ }^{28}$

\section{Función de los corrales}

\section{a) Matadero}

La construcción de los corrales mandada ejecutar por el gobernador Sobre Monte, tuvo como fin el ordenar la actividad y circunscribir la zona de la matanza de reses por tres razones principales:

1. para controlar que las reses que se introducían y vendían estuvieran en condiciones y no fuesen robadas.

2. para cuidar la higiene y salud de la ciudad.

3. para aumentar los ingresos de propios.

Las reses que entraban en los corrales podían destinarse para el abasto diario de la ciudad o ser vendidas a otros hacendados. Las introducciones las hacían los propios hacendados o sus peones y los abastecedores que vivían, precisamente, de la tarea de abastecer de carne a la población. Se cuidaba en especial que no se introdujeran reses robadas, dañadas o hembras, éstas últimas para proteger el procreo. ${ }^{29}$

El mayordomo de corrales establecía las horas de matanza y presenciaba diariamente, auxiliado por el fiel de medidas, el corte de las porciones de carne señaladas, según fuera tiempo de escasez o abundancia. Por su parte, los carretilleros - tema de otro traba-

27 Rojas de Villafañe, Emilio: La economía de Córdoba en el siglo XIX, Córdoba, 1976, pág. 54.

28 Ver lám. 4. Una fotografía de este plano se encuentra en el Instituto de Estudios Americanistas y algunos dibujos parcelados en publicaciones del Padre Grenón.

29 AHPC, Gobierno, año 1794, Caja 15, carp. 3, fol. 131. 
jo- eran quienes conducían la carne a la plaza para su venta al menudeo. ${ }^{30}$

Los vecinos de los corrales se quejaban repetidamente de la corrupción que producía la matanza y tornaba irrespirable el aire en las cercanías del matadero. El síndico procurador, en 1803, se refería a estas quejas y consideraba que podía pagar cada matancero medio real por mes para invertirlo en la limpieza y acarreo de los desperdicios que causaba su ejercicio, debiendo recaudarlo el mayordomo de corrales. ${ }^{31}$

Unido al funcionamiento del matadero surgió también la necesidad de limpiar las zonas aledañas a él. Ya en 1780 se había prevenido:

“...los matanceros levanten de las calles las inmundias (sic), y retiren para la parte del poniente donde no reciva mal olor el pueblo o enterrandolo en alguna sanja, interin otra cosa se determina" ${ }^{32}$

Para 1787 don Bernardo Vilar es el encargado de controlar la limpieza de las calles. Algunos vecinos contribuían con medio real al mes para abonar la carretilla de bueyes que diariamente las limpiaba. La principal causa del desaseo la originaban las carretas de abastos que pasaban por la ciudad, por ello el procurador de ciudad informaba en febrero de 1787 que el único arbitrio factible para subvencionar la limpieza era gravar dichas carretas con medio real. ${ }^{33}$

Todo el ganado pagaba el derecho llamado de piso, consistente en medio real por cabeza, destinado a engrosar los ingresos de propios de la ciudad. El origen y evolución de este impuesto lo analizaremos posteriormente en este trabajo.

30 Ibídem. Martínez de Sánchez, Ana María: Contribución al estudio de los abastos en América durante el período hispánico. El abasto de carne a la ciudad de Córdoba (17831810), en "Jahrbuch für Geschichte von Staat, Wirtschaft und Gesellschaft Lateinamerikas", tomo 23, Colonia, 1986, pág. 205.

31 AHPC, Escribanía 2, año 1803, leg. 105, exp. 17. Fue común en toda la América española que el Procurador se ocupara del aseo de la ciudad en general y en estos casos concretos en particular. Seoane, María Isabel: Buenos Aires vista por sus procuradores (1580182I), Buenos Aires, 1990, pág. 149.

32 AMC, Actas Capitulares, Libro trigésimo sexto, fol. 197r.

33 Instituto de Estudios Americanistas (en adelante IEA), Fondo documental, doc. n." 4309. 


\section{b) Alquiler}

Los trascorrales y alrededores del matadero sirvieron para mansión de tropas.

Recordemos que Córdoba era punto principal del comercio de mulas y nudo de comunicaciones con el norte, oeste y litoral. Antes de la construcción de los corrales en la ciudad, los que introducían ganado para el abasto debían alquilar diariamente corrales a los particulares, quienes no les cobraban menos de lo que luego abonaron en los corrales del Rey. El dueño del corral no se hacía responsable de las pérdidas que pudieran ocasionarse ni diferenciaba para el pago del alquiler que el ganado se vendiese o retornase a las zonas de pastos. ${ }^{34}$

Los corrales de la ciudad prestaron un servicio muy beneficioso para los troperos ya que así tenían albergue seguro para su ganado, protegiéndolo de los robos, igual que a los hacendados que introducían reses no destinadas para el abasto.

Lo producido por la entrada de arrias y carretas a la plaza fue un arbitrio autorizado por el Rey para solventar los gastos de construcción de la cárcel y casa capitular, junto con el Ramo de carretillas. No lo receptaba el mayordomo de corrales sino persona diputada al efecto. ${ }^{35} \mathrm{El}$ derecho de piso que pagaban las arrias y carretas ascendía a 20 reales, es decir 2 pesos, 4 reales.

Las arrias procedían principalmente de San Juan, Catamarca y La Rioja, mientras que tropas de carretas, cargadas de diversos efectos, llegaban de Tucumán, Buenos Aires, Santa Fe y Mendoza.

34 AHPC, Escribanía 4, años 1794-1795, leg. 6, exp. 14.

35 Los bienes propios de ciudades y villas eran las fuentes de recursos con que afrontaban los gastos del común, sin tener que recurrir a las derramas; recordemos que entraban en el concepto de propios los bienes comunales como leña, pastos, etc. En general, aunque no siempre fue así, los propios se ponían en bienes raíces o estables: tiendas, molinos, solares, campos o casas. Cuando estos propios no alcanzaron para cubrir las necesidades del común, por ejemplo pagar las obras públicas imprescindibles para la ciudad, se arbitraron medios para hacerlo y así surgieron los arbitrios como la renta de pulperías, producto de carnicerías, arriendos, etc. De allí que las cuentas que rendía el mayordomo de propios al tesorero de Real Hacienda se titularan de "Propios y arbitrios". Bayle: Los Cabildos seculares.. págs. 301 y ss. 


\section{Construcción de los corrales del Rey. Su traslado}

\section{Los corrales del Rey de 1786}

Los corrales que ordenó construir el gobernador intendente Sobre Monte, según hemos ubicado en el apartado anterior, estaban emplazados en la zona norte de la ciudad, fuera de los predios correspondientes a la traza, en la orilla del cauce del río que había unificado allí el brazo que antes corría en la ronda de la ciudad. ${ }^{36}$ Recordemos que las Leyes de Indias mandaban que las tenerías, pescaderías, mataderos, etcétera, debían construirse cerca de los ríos caudalosos para que ellos arrastraran toda la inmundicia que producían.

Sin embargo, estos corrales no aportaron la higiene que se buscó con su contrucción. En el expediente formado sobre la traslación de los corrales aparecen valiosos datos que nos permiten conocer de qué manera se manejaron los primitivos. Algunos vecinos presentaron un memorial que decía:

"Todos los físicos de mejor nota en el día enseñan y la razon lo convence que las pestes, epidemias y demas males corruptivos, como escorbutos, loandas, etcetera, que se experimentan en las poblaciones y en los navíos provienen (entre otras causas) de la infeccion del aire que respiramos, el que corrompido introduce tambien por el aliento la corrupcion a nuestros humores principales hasta causar muchas veces la gangrena en la masa de la sangre..." 37

Atribuían a la situación de Córdoba, en un bajo, la falta de aire ventilado y continuaban diciendo:

“...y si a estas causas se les añade la otra de la corrupcion de los corrales (fuera de las demas que son inevitables) por presision ha de aumentarse el efecto. En ellos asi por las inmundicias de la matanza como por aquellos fetidisimos lagos, morada perpetua de los puercos son continuas las corrupciones que se engendran de dia en dia las que segun el viento se perciben muchas veces en los varrios mas centrales siendo aquellos cercanos casi insufribles por estar allí siempre impregnado el aire y repleto de vapores cepticos y putridos.

36 AHPC, Gobierno, años 1802-1803, Caja 24, carp. 5, fol. 455.

37 Ídem. 
Esta diaria fermentacion no puede bastantemente disiparse por el concabo de Cordoba en que no baten con libertad los aires. A esta circunstancia se añade la otra de estar los Corrales a la parte del Norte viento que sobre calido y seco, es aqui el dominante y á cuyo favor necesariamente ha de entrar en el pueblo en copiosas avenidas toda aquellas corrupcion, que a su tiempo ha de producir y produce sus efectos". ${ }^{38}$

Apuntaron que en la zona más cercana a los Corrales era donde acudía con más frecuencia el viático en tiempo de epidemias. De acuerdo a lo expuesto, nadie duda del perjuicio que causaban los corrales, cuyo mal se sumaba a la fetidez de otros lugares que tenía la ciudad como cárceles, camposantos y los templos, que cumplían la función de cementerios.

El procurador de ciudad había efectuado su alegato sobre la necesidad de construir corrales para la introducción de ganados de la jurisdicción, destinados al abasto, y de los de fuera de ella que entraban en época de carestía.

El lugar debía estar a proporcionada distancia de la población. La elección del sitio apropiado - aunque después presentó los inconvenientes expuestos por los vecinos, que transcribimos al comienzo de este apartado - la habían realizado el alcalde de primer voto, el regidor Florencio García y el procurador general de ciudad. ${ }^{39} \mathrm{El}$ manejo de la construcción se encargó a Miguel Vázquez y en febrero de 1786 el gobernador Sobre Monte aprobó el expediente formado sobre la construcción. ${ }^{40}$

El procurador redactó la instrucción correspondiente acerca de la formación de los corrales y su manejo por el mayordomo, que fue aprobada por el Cabildo. El mayordomo de corrales y el fiel ejecutor debían presentar cualquier dificultad que se les ofreciera en punto a su cumplimiento para, de acuerdo a ello, reformar lo que se creyera conveniente. ${ }^{41}$

38 Ídem.

39 AMC, Actas Capitulares, Libro trigésimo séptimo, fol. 192r.

40 AHPC, Gobierno, año 1786, Caja 8, carp. 5. AMC, Actas Capitulares, Libro trigésimo séptimo, fol. 199r.

41 Ibídem, fol. 197r. Acuerdo de 24 de enero de 1786. Ver apéndice documental. 
El primer año de funcionamiento (1786) los corrales tuvieron un rendimiento muy corto: 156 pesos, de los cuales la construcción llevó $141 .{ }^{42}$ Sobre el tamaño de la construcción sabemos que en 1789 los corrales acondicionados eran 10 , todos con puerta y aldabón, y que había 45 trancas y 15 palos para reforzarlos. ${ }^{43}$

Las características de los corrales y sus materiales (palos y cueros), sumado a la función que cumplían, hicieron de ellos una construcción muy vulnerable. Cada año encontramos peticiones para su reparación y las cuentas de las obras que se hacían a cargo del Ramo. En acuerdo capitular de 15 de abril de 1791 ya se trató un expediente promovido a solicitud del mayordomo de corrales, para que se encarase la reparación por estar "casi del todo arruinados". ${ }^{44}$ En enero del siguiente año, el mayordomo elegido, Juan Francisco Aguirre, hizo presente al señor gobernador el estado de inutilidad en que se hallaban sus cercos:

“...causado del exercicio y de las frecuentes llubias que afloxando la tierra y el corambre que sugeta su estacada hace perder esta, de que se originan los daños, y perjuicios que considerablemente sufren los dueños del ganado y de consiguiente el ramo..." 45

Los pagos se cubrían con los gastos de $4 .^{\text {a }}$ clase, de conformidad al Reglamento de Propios elaborado por Sobre Monte. ${ }^{46}$ Los que suministraban los cueros para los arreglos eran los mismos matanceros, es decir que ellos disponían de los cueros provenientes de la matanza. ${ }^{47}$

42 IEA, Fondo documental, doc. n. ${ }^{\circ} 3734$.

43 AMC, Cabildo Documentos, 1787-1790, fol. 191r.

44 AMC, Actas Capitulares, Libro trigésimo octavo, fol. $141 \mathrm{v}$.

45 AMC, Cabildo Cuentas, 1790-1794, fol. 293r. Para su composición se necesitaron 400 palos. La mano de obra que se utilizó para ésta y las sucesivas reparaciones fue siempre proveniente de la cárcel, por lo cual sólo se abonaba su manutención -yerba y carne- porque solían presentarse con las herramientas necesarias. Casi todas las obras públicas se hicieron con este tipo de mano de obra. Las penas impuestas para muchos delitos y, especialmente, para el de abigeato eran el trabajo en obras públicas. Martínez de Sánchez, Ana María: El abigeato en Córdoba en el último tercio del siglo XVIII, en "Revista de Historia del Derecho", n. ${ }^{\circ}$ 18, Buenos Aires, 1990, pág. 233.

46 IEA, Fondo documental, doc. n. ${ }^{\circ} 7023$.

47 AMC, Cabildo Cuentas, 1790-1794, fol. 295 y ss. 
En 1794, por un expediente de demanda de indemnización por perjuicios causados a un introductor de ganado, ${ }^{48}$ conocemos que el estado de los corrales no era ideal. Se menciona la inseguridad de los trascorrales - ocho de ellos inutilizados por falta de tranqueras - y se describe la debilidad de las trancas, el estado de los candados, etc. ${ }^{49}$ Años después, en julio de 1802 , el mayordomo de corrales Juan Manuel Ramallo, hizo presente al gobernador intendente interino que los corrales se hallaban muy deteriorados y era necesaria su reparación para que no aumentara el costo del arreglo con el aumento de su ruina. Denunció, también, la necesidad de atajar el brazo del río que corría por sus inmediaciones, ya que por el norte los corrales estaban expuestos a las crecientes del río en verano.

Pérez del Viso aprobó el gasto y señaló la intervención del diputado de obras públicas para que abordara el tema de las inundaciones. ${ }^{50}$ Desde marzo de 1803 comienzan a tratarse escritos presentados por algunos vecinos solicitando la traslación de los corrales a la barranca del Pucará. ${ }^{51}$

\section{Traslado de 1805}

Conocemos ya los inconvenientes que causaban los corrales en mal estado a los ganaderos que veían perder su ganado por la inseguridad que ellos ofrecían. ${ }^{52} \mathrm{Su}$ proximidad al río, que los hacía vulnerables en la época de crecientes, y la poca higiene que mostraban, debido a que estaban más bajos que el río y las aguas de lluvia no corrían, fueron algunas de las causas que determinaron su traslado.

48 AHPC, Escribanía 3, año 1794, leg. 48, exp. 9.

49 AMC, Cabildo Cuentas, 1794-1800, fol. 4r. Las cuentas de este arreglo sumaron 132 pesos 3 y $1 / 2$ reales.

50 Ibídem, 1800-1808, fol. 88r. Se gastaron 136 pesos, 4 reales para los reparos. Se utilizaron 2300 palos, cuero, came para la alimentación de los presos que trabajaban. Todo se pagó de los gastos de $4 .^{2}$ clase.

51 AMC, Actas Capitulares, Libro cuadragésimo segundo, fol. $11 \mathrm{r}$.

52 AHPC, Escribanía 3, año 1794, leg. 48, exp. 9. 
Los vecinos, abastecedores y médicos de la ciudad emitieron su opinión sobre la situación de los corrales y las aspiraciones futuras. Los médicos fueron: don Pablo Pastor, cirujano del Colegio de Cádiz; don Gerónimo Ameller y don Miguel del Mármol, médico de la Real Cárcel.

Todos coincidieron en los puntos de gravedad, haciendo, en el caso de los facultativos, un sinnúmero de citas enuditas sobre las definiciones de peste y epidemia. Decía el doctor Pastor:

“...el transporte del matadero en paraje que esté a un rumbo que no nos venga de el los vientos y que su plano sea superior al Rio para que las aguas puedan arrozar (sic) sus fragmentos corrompidos que suelen quedarse al az de la tierra; podra ser este uno de los medios de evitar las epidemias de calenturas putridas, que en los cinco años que tengo el honor de exercer mi facultad en esta ciudad he observado reynante desde junio hasta mediados de septiembre, que si se verificase extinguirlas o minorarlas, lograria este publico un sumo veneficio..."

Ameller agregó a estos pareceres, que llevaba 28 años avecindado y que desde hacía unos años notaba más muertes repentinas en épocas de seca y de calor, lo que atribuía a la situación de los corrales que infectaban el aire. Decía:

"En tiempo del Señor Marques de Sobremonte Gobernador que fue de esta provincia le informe de palabra varias veces quan perjudicial hera a este pueblo el Parage donde se hallaban los Corrales y que si esta ciudad tuviera fondos con que pudiera construir un puente del parage de esta parte, al rio de la otra banda seria la mejor situacion en que podian establecerse los Corrales, pues de esta suerte se aumentaria mas la poblacion y gozaria esta ciudad mas felicidad en las epidemias que en ciertas ocasiones del año experimenta como son entrada de invierno y salida de verano..." 53

Como no había fondos para concretar su proyecto o sugerencia, apoyó la idea general de que los corrales se trasladaran al Pucará. El procurador, considerando todo lo expuesto, conceptuó convenien-

53 AHPC, Gobierno, año 1802-1803, Caja 24, carp. 5, fs. 457 y ss. y Gobiemo, año 1805, Caja 27, carp. 5, fol. 718. 
te su traslado "...al sitio inmediato a la barranca colorada llamada por los naturales Pucará”.

A esa altura el río ya había atravesado toda la ciudad y arrastraría la putrefacción hacia la zona despoblada. Este traslado no interceptaría de ningún modo la comercialización de la carne en la plaza ya que estarían de ella a la misma distancia que estaban los corrales viejos, pero hacia otro rumbo.

El 2 de marzo de 1804 el Cabildo nombró a los regidores don Antonio Savid y don Pedro Ignacio Mugica para que examinaran el paraje. ${ }^{54}$ Inmediatamente comunicaron su parecer al Cabildo y nombraron a Ramallo para que, a la brevedad, con anuencia de los señores diputados, ejecutara la obra comprando lo necesario mediante libranzas de la Junta de Propios. ${ }^{55}$

Para junio de ese año ya estaba en marcha la obra, por lo menos en lo referido a compra de material, ya que en julio se reclamaba por la demora en la iniciación de la construcción debido a que no se habían podido acopiar todos los palos necesarios. ${ }^{56}$

Juan Manuel Ramallo compareció ante la sala capitular para explicar que la causa por la que no se había puesto aún planta era por no saberse de dónde se echaría mano para los gastos indispensables de manutención de los corrales. Los señores capitulares pasaron oficio de esto al gobernador para que estimara lo más conveniente. ${ }^{57}$

Un oficio del gobernador intendente presentado al Cabildo el 3. de agosto de 1804, indicó: “...que el dia lunes seis del corriente precisamente se de principio a los nuevos corrales". ${ }^{58}$ Estaban ya listas las herramientas y los presos que debían trabajar en la obra. A fines de ese mes se decidió que se hiciera:

54 Mugica, por estar retirado del Cuerpo por orden del gobernador, fue reemplazado el 6 de abril de 1804 por Francisco Pérez Mier. AMC, Actas Capitulares, Libro cuadragésimo segundo, fol. $122 \mathrm{v}$.

55 Ibídem, fol. 101v. y ss. AHPC, Gobierno, año 1802-1803, Caja 24, carp. 5, fol. 458 y ss.

56 AMC, Actas Capitulares, Libro cuadragésimo segundo, fol. 137r.

57 lbidem, fol. 143v.

58 Ibídem, fol. 146v. 
“...un corral y trascorral a espaldas de los corrales nuevos para encerrar mulas, caballos y boyadas pagandose cada noche aquellas cuatro reales y los demas a dos en beneficio de los propios de ciudad cuya administracion debe correr a cargo del Mayordomo de Corrales quien debera llevar cuenta por separado de este producto, designando el numero de especies y sus contribuyentes.." 59

Finalizando diciembre estaba el corral y trascorral terminado con un gasto mínimo de 40 pesos 3 y $1 / 2$ reales, ya que se utilizaron los palos de los corrales viejos. ${ }^{60}$ Pero el nuevo emplazamiento también fue vulnerable por su vecindad al río y a poco de terminados comenzaron las reparaciones. ${ }^{61}$

En 1808 se realizó una nueva reparación y se hizo un cuarto habitación para su mayordomo. ${ }^{62}$ A fines de 1810 , nuevamente el mayordomo, entonces Baigorri, se quejaba del estado de deterioro en que había recibido los corrales y lo necesaria que resultaba su reparación. ${ }^{63} \mathrm{~A}$ comienzos de 1811 aún siguen los arreglos que continúan reclamándose en 1813 , mientras ya se hablaba de hacer un nuevo traslado de los corrales a la parte alta del Pucará. ${ }^{64}$

59 Ibidem, fol. 151r. y v.

60 AHPC, Gobierno, año 1806, Caja 28, carp. 5, fol. 502. Don Francisco Pérez Mier y don Filiberto Villalba presentaron la cuenta de los gastos que requirieron los nuevos corrales, devolviendo 20 pesos y 1 real de sobrante. AMC, Actas Capitulares, Libro cuadragesimo tercero, Córdoba, 1969, pág. 60.

61 En 1807 el mayordomo don Manuel Oliva pagó a Francisco Tisera 35 pesos y 4 reales, por veintiuna carretadas de palo para los "Corrales del Rey" y una de tranqueras. En ese momento fallaba la orconería, lo que ponía en peligro el ganado encerrado. AMC, Cabildo Cuentas, 1800-1808, fol. 319. La planilla de gastos indica que se usaron 74 cueros y se trabajó durante 62 días en la reparación, siendo todo abonado por cuenta del mayordomo de corrales. En julio de 1808 nuevamente se repararon los corrales a cargo, dicha obra, de don Andrés Avelino de Aramburú. El depositario de propios le entregó 200 pesos al efecto. AHPC, Gobierno, año 1809, Caja 31, carp. 3, fol. 282. fol. 346.

62 La obra costó 436 pesos, 1/2 real, AHPC, Gobierno, año 1809, Caja 31, carp. 3,

63 Para este arreglo se invirtieron 27 pesos 4 reales, en palos y "señas" hechas y numeradas por un platero. A los peones se les pagó 15 pesos $1 / 2$ real por hacer "la palisada que voltió el río". AMC, Cabildo Cuentas, 1808-1816, fol. 60r., 64r. y 68v.

64 AHPC, Gobierno, año 1811, Caja 33, carp. 2, fols. 267 y 298. AMC, Actas Capitulares, Libro cuadragésimo sexto, Córdoba, 1960, pág. 265. 


\section{El mayordomo de corrales. Sus funciones}

Desde la fundación existió el mayordomo de ciudad. Era un cargo de nombramiento capitular cuya función era administrar los bienes del Cabildo. En los pueblos chicos se confundió con el mayordomo diputado de propios y tesorero de Cabildo. ${ }^{65}$

Cuando la ciudad creció y las tareas se diversificaron surgió el mayordomo de corrales que, como el de ciudad, tenía a su cargo la administración de una parte de los bienes que ingresaban como del común.

El cargo aparece como tal en 1787 cuando en la elección capitular de primero de enero de ese año se designa a Miguel Vázquez. Sin embargo, su origen lo encontramos en 1786 cuando, tratándose en reunión de Cabildo de 9 de enero de ese año los asuntos referidos a carne y construcción de corrales y matadero, se designa para el manejo de ellos a Miguel Vázquez. En ese momento se le asignó la mitad de su producto y se le comisionó para la construcción de los corrales bajo las reglas y plan que se le diere. Quedaban también a su cargo los reparos que hubiera que hacer para la conservación. ${ }^{66}$

El procurador general fue diputado para que formara una instrucción, como lo hizo - que se tuvo presente en el acuerdo de 24 de enero de 1786 - sobre el manejo que debía tener el mayordomo y el fiel ejecutor y sobre la formación de los corrales y arreglo de la venta de la carne. ${ }^{67}$ Los nombramientos se hacían el 1 de enero de cada año, salvo cuando se posponían por algún motivo circunstancial o cuando se realizaban en el mes de octubre para cubrir los cargos del período siguiente.

Las obligaciones del mayordomo eran cuidar los corrales, cobrar los derechos impuestos y, en especial, llevar cuidadosa cuenta de lo que entraba al Ramo de Propios como ramo de corrales. De acuerdo a la instrucción redactada por el procurador debía contro-

65 Bayle, Los Cabildos seculares..., pág. 267.

66 AMC, Actas Capitulares, Libro trigésimo séptimo, fol. 192r.

67 Ibídem, fol. 183v. y 197r. Ver apéndice documental. 
lar celosamente que no se menudeara la carne fuera de la Plaza, ayudado por el fiel ejecutor. Esto beneficiaba a los mismos que allí la vendían evitando que se expendiera al público según el arbitrio de cada uno, lo que les proporcionaría excesivas ganancias "que no son permitidas en alimento de primera necesidad". ${ }^{68}$

También era obligación del mayordomo de corrales avisar al fiel ejecutor el precio a que se vendían las reses en pie y su calidad, para poder arreglar el precio en la plaza. Esto aseguraba que el servicio al público fuera brindado con equidad y justicia, proporcionándole la correspondiente ganancia al que vendía. ${ }^{69}$

El severo control de los ganados que entraban en los corrales permitió restringir los frecuentes robos o por lo menos, evitar que los abigeos se deshicieran de las reses a través del abasto a la ciudad. La venta para el abasto era el modo más fácil de convertir en dinero lo robado. Otra salida era trasladar el ganado a otras regiones para venderlo, modo más difícil y en el que se invertía más tiempo. Por ello el mayordomo verificaba que las reses que entraban hubiesen sido legítimamente adquiridas informando de qué paraje provenían y a quien habían sido compradas. ${ }^{70}$ Llevaba un libro de entrada de ganado y rendía cuentas a la Junta Municipal de Propios y Arbitrios cada seis meses. ${ }^{71}$

"El Mayordomo de Corrales tendrá especial cuidado de intervenir en las ventas y compras del ganado del habasto que hicieren los traficantes Matanceros, u otras personas para evitar qualquier trato fraudulento y perjudicial al Publico y de que no se hagan reventas en el tiempo de escasez que puedan ser usurarias y causar la mayor pena de que el que lo executare pierda el precio de la res vendida en beneficio del perjudicado u otra arbitraria siendo mayor el numero, a disposicion de este Govierno, con 25 pesos de multa al mayordomo

68 AHPC, Gobierno, año 1786, Caja 8, carp. 2, fol. 136r.

69 Ibídem.

70 AMC, Actas Capitulares, Libro trigésimo séptimo, fol. 185r. Sobre robo de cuatropea ver Martínez de Sánchez: El abigeato en Córdoba..., págs. 225-246, y de la misma autora Contribución al estudio de los abastos en América... pág. 201.

71 IEA, Fondo documental, doc. n. ${ }^{\circ}$ 3734. Lo que se rendía como Ramo de corrales se integraba a lo recaudado por alquiler de la recova, pulperías, canchas, etc. El libro de entrada de ganado no lo hemos hallado en ninguno de los repositorios consultados. 
si lo tolerase o dicimulare quando en el trato mediare conosida usura y perjuicio facultandose al Matancero para que pueda denunciarle semejante exceso a fin de proporcionar los medios de corregirlo por todos los terminos..." 72

El mayordomo de corrales era recompensado por su trabajo con un porcentaje. Una vez aprobado por el Cabildo el derecho que debían pagar los conductores de ganado y recomendada su puntual recaudación, se decidió:

“...que el mayordomo de Corrales por el mucho trabajo que ha de impender tanto en la recaudación quanto en la subsistencia y renovacion de los mismos corrales se le asigne el veinte y cinco por ciento de todo lo que quedase liquido sacados los gastos, que se imbiertan en la reparación de dichos corrales..." 73

El mayordomo era responsable de las reses que quedaban en el corral. Esta fue una de las causas por la que ellos se ocupaban de que estuvieran en buen estado, pues así aseguraban la protección de las reses.

En 1794 se acusó a Juan Francisco Aguirre por su poca asistencia a los corrales, en razón de unas cabezas que se escaparon. ${ }^{74}$ Al analizar este expediente hemos podido conocer que no tenían obligación de pasar la noche en ellos. Sólo asistían de día hasta la oración y luego se retiraban a su casa, ya que hasta 1807 no se construyó un cuarto habitación para el mayordomo. ${ }^{75}$ Los matanceros debían cerrar la puerta cada vez que entraban ganado, para evitar la salida del mismo hasta que, a la oración, el mayordomo la cerraba hasta el día siguiente.

Las personas que desempeñaron el cargo en el período estudiado fueron:

1786: Miguel Vázquez (encargado)

1787: Miguel Vázquez (nombrado)

72 AHPC, Escribanía 4, año 1796, leg. 7, exp. 11.

73 AMC, Actas Capitulares, Libro trigésimo séptimo, fol. 252r. Córdoba 19 de enero de 1787. IEA, Fondo documental, doc. n. ${ }^{\circ} 3734$.

74 AHPC, Escribanía 3, año 1794, leg. 48, exp. 9.

75 Ver párrafo de nota 62. 
1788: Manuel de Urtubey

1789 y 1790: Bernardo Vilar

1791: Miguel Vázquez

1792 y 1793: Juan Francisco Aguirre

1794 a 1804: Juan Manuel Ramallo

1805: Agustín Arraigada

1806 a 1809: Manuel Oliva

1810: Agustín Arraigada

1811 y 1812: José Tomás Baigorri

\section{El Ramo de corrales}

El procurador general indicó en diciembre de 1785 , cuando se ordenaba sobre el manejo de los corrales de inminente habilitación:

“...como introductores del ganado deberan pagar un real por cada noche de la que esté en el Corral, que es lo mismo que han acostumbrado pagar a los particulares: declarando a los matanceros que comprasen a estos introductores dentro del corral alguna parte exemptos de esta contribucion, menos quando ellos mismos sean los introductores de lo que conduzcan de los rodeos de la jurisdiccion o fuera de ella." 76

A partir de esto los matanceros inventaron el fraude; exceptuados de contribuir el real que estaba mandado, introducían el ganado de otros. En 1786 los corrales produjeron menos de lo esperado. De acuerdo a los informes que Sobre Monte solicitó al mayordomo Miguel Vázquez, la escasa utilidad del Ramo se debió a que la mayor parte del ganado que se había encerrado no había permanecido durante la noche. Las cabezas destinadas a la matanza para el abasto de la ciudad salían el mismo día de su entrada.

Para evitar este perjuicio y aumentar los propios -que fue uno de los fines por el cual se construyeron- propuso Vázquez que se cobrara $1 / 2$ real por cabeza que entrase y encerrase, se mantuviera uno o muchos días en ellos. Ese medio real lo pagarían los dueños

76 AMC, Actas Capitulares, Libro trigésimo séptimo, fol. 187r. 
que lo introdujesen y no los matanceros que lo compraran, aunque éstos no lo expendieran en el día y lo mantuvieran en ellos hasta concluir la matanza. ${ }^{77}$

Cuando a Vázquez se le pidió la pormenorización de los fraudes que se hubieran experimentado en ese año de 1786, respondió que los que introducían para el abasto (matanceros) tomaban a su nombre la mayor parte del ganado o varias porciones de distintos sujetos para evadir la contribución o alquiler. ${ }^{78} \mathrm{Su}$ proyecto de que se cobrara a todos medio real por cabeza fue aprobado, aplicándose a partir de ese momento a todas las reses que se consumieran o vendiesen.

El mayordomo de corrales dio a conocer sus observaciones. Los conductores de ganado defraudaban el $1 / 2$ real de impuesto, también, cuando no vendían sus reses y las retiraban, so pretexto de volverlo y luego lo vendían, unas veces a los troperos y pasajeros, otras a los mismos vecinos que los conducían a sus estancias y potreros, y otras a los conventos y comunidades religiosas que hacían su propio faenamiento. Con esta maniobra quedaba frustrada una superior providencia de 2 de enero de 1787, librada a la vista de los cortos productos del Ramo de corrales y de lo que entonces había informado el Ilustre Cabildo.

Era un fraude imposible de evitar por lo difícil que resultaba averiguar las ventas clandestinas. En febrero de 1794 el teniente asesor ordenó:

"Por ausencia del Señor Marques de Sobre Monte se hace saber a todos los que introdujesen ganados a los Corrales del Rey que luego y en el acto de su ingreso a ellos han de satisfacer el medio real establecido por cabeza o a lo menos entregar prenda equivalente al derecho que adeuden, hasta en el entretanto se satisfacen, con el bien entendido que quedan reatados a esta satisfaccion en el todo del numero introducido, vendase o no respecto a que si por algun evento y descuido del Mayordomo se profugan, queda este responsable". ${ }^{79}$

77 Ibidem, fol. 252r. y v. IEA, Fondo documental, doc. n. ${ }^{\circ}$ 3734. AHPC, Gobierno, año 1787 , caja 9 , carp. 1 y 5 .

78 Ídem.

79 AHPC, Escribanía 4, años 1794-1795, leg. 6, exp. 14. 
El mayordomo consideró justa esta medida, ya que ese medio real no debía considerarse como un impuesto sino el precio por el alquiler de los corrales, sobre todo teniendo en cuenta que él se responsabilizaba por todo el ganado. El que alquilaba una casa para guardar mercadería o metía en invernada su ganado no dejaba de pagar por no vender. Si él respondía por todas las cabezas, todas debían contribuir dejando algo para él y para el dueño de los corrales, en este caso la ciudad.

La orden dada por Pérez del Viso beneficiaba al ramo aportándole mayor producto. Si se quitaba se aminorarían las entradas y los ingresos del mayordomo, de tal forma que, en poco tiempo, nadie querría tener el cargo. ${ }^{80} \mathrm{La}$ idea de establecer este derecho tuvo dos motivos, que coincidían con los de la construcción de los corrales: evitar los robos y aumentar los propios.

En esta época en los corrales se encerraba todo el ganado destinado al abasto y el que quería venderse con otro destino. Allí se regulaban las operaciones como se hacía en Lima, Cuzco y Chuquisaca. ${ }^{81}$

La decisión tomada por el teniente asesor Pérez del Viso no tuvo mucha vigencia. En abril de 1785, Sobre Monte, a pesar de las justas razones que había invocado su reemplazante, consideró un expediente que se le había presentado y modificó lo dispuesto.

Advirtió al mayordomo que cesase en la recaudación del medio real por cabeza de las reses que no se vendieran para el abasto, no entrando en esta excepción las que se introdujeran con otros fines, ni las que de cualquier modo se vendiesen. La medida, según argumentaba, tendía a aliviar a los hacendados y vendedores que, por no poder despacharlas para el abasto, se veían obligados a restituirlas a sus estancias o a otros pastos.

La orden de Sobre Monte, que se comunicó al Cabildo, al regidor de plaza y al mayordomo de corrales, estableció además, que de allí en adelante sólo se cobraría los domingos medio real por res, en lugar del real que pagaban para satisfacción de la alcabala de los

80 Ídem.

81 Ídem. 
cueros a que estaban obligados. Lo que se recaudaba de este modo alcanzaba a cubrir los gastos de los corrales, fiel de medidas, etc., según apuntaba el gobernador intendente. ${ }^{82}$

Esta modalidad de tributar en los corrales se extendió hasta el fin del período que estudiamos, formando su producto el llamado "Ramo de corrales". ${ }^{83}$

CUADRO QUE MUESTRA LOS PRODUCTOS ANUALES DEL RAMO

DE CORRALES Y EL TOTAL DE PROPIOS ENTRE 1786 Y 1796

(EN PESOS Y REALES).

Año

Ramo de corrales

Total de Propios

1786

1787

156

$1.670,31 / 4$

1788

1789

no hallado

$1.128,5$

427,66

$1.277,, 7$

409,1

$1.045,, 1 / 4$

1790

$316,, 5$

$1.109,33 / 4$

1791

$319,, 7 \quad 1 / 2$

$1.227,7$

1792

$362,21 / 2$

$1.744,, 7$

1793

379

$2.118,, 5$

1794

412,4

$1.625,, 1 / 2$

1795

$527,, 3 \quad 1 / 2$

$2.226,4$

1796

$661,, 31 / 2$

no hallado

No contamos con cifras completas que nos muestren el grado de importancia que tuvo el Ramo de corrales en las cuentas generales de propios de la ciudad, para todo el período que trabajamos.

Hemos podido formar solamente una secuencia de los diez primeros años que funcionaron los corrales. El producto del Ramo que

82 AHPC, Gobierno, año 1795, Caja 16, carp. 2, fol. 120. AMC, Actas Capitulares, Libro trigésimo noveno, fol. 94v.

83 Ver el cuadro que incluye los productos anuales del Ramo de Corrales y el total de propios, entre 1786 y 1796, en que pudo reconstruirse la secuencia completa. 
aparece en el cuadro es el líquido, descontado ya el $25 \%$ que correspondía al mayordomo por su trabajo y los gastos que ellos mismos insumían.

El Ramo de arrias y carretas y el de carretillas, constituye montos aparte de los expuestos.

Disponemos de datos aislados para 1802, 1807, 1808 y 1810, que incluímos a continuación:

Ramo de corrales

Total de Propios

\begin{tabular}{|c|c|c|}
\hline 1802 & $536,7 \quad 1 / 2$ & $2.942,, 3$ \\
\hline 1807 & $789,11 / 2$ & no hallado \\
\hline 1808 & $856,4 \quad 1 / 2$ & 4.963 \\
\hline 1810 & $789,1 \quad 1 / 2$ & $4.672,, 6^{84}$ \\
\hline
\end{tabular}

\section{Conclusiones}

Córdoba contó con corrales y matadero definitivos desde 1786, por iniciativa de Sobre Monte y los vecinos de la ciudad. Se cubría así una necesidad que beneficiaba a los matanceros y se engrosaban los propios de la ciudad mediante el pago del derecho que estableció a las cabezas de ganado que se encerraban en ellos.

En 1786 se construyó un corral en la zona norte, fuera de la traza, y en 1805 se trasladaron por razones higiénicas, emplazándose al sudeste en el bajo que formaba el Pucará que protegía naturalmente los corrales.

Se encomendó su administración al mayordomo de corrales, cargo que siempre fue cubierto en el período que investigamos. Algunos se mantuvieron muchos años, como el caso de Juan Manuel Ramallo, yerno del escribano Matos de Azebedo.

84 Las cifras expuestas han sido recogidas en el AMC, Cabildo Cuentas, 1791-1796, 1794-1800, 1790-1794, 1800-1808 y 1808-1816. Cabildo Documentos, 1780-1787, 1787-1790 y $1727-1866$. 
El Ramo de corrales permitió que se dispusiera, dentro de los propios, de cierto caudal para cubrir los gastos del común.

Los corrales de la matanza constituyeron un avance muy importante en la evolución de los abastos de la ciudad, en el conjunto de medidas que concretó el progresista gobierno del marqués de Sobre Monte. 


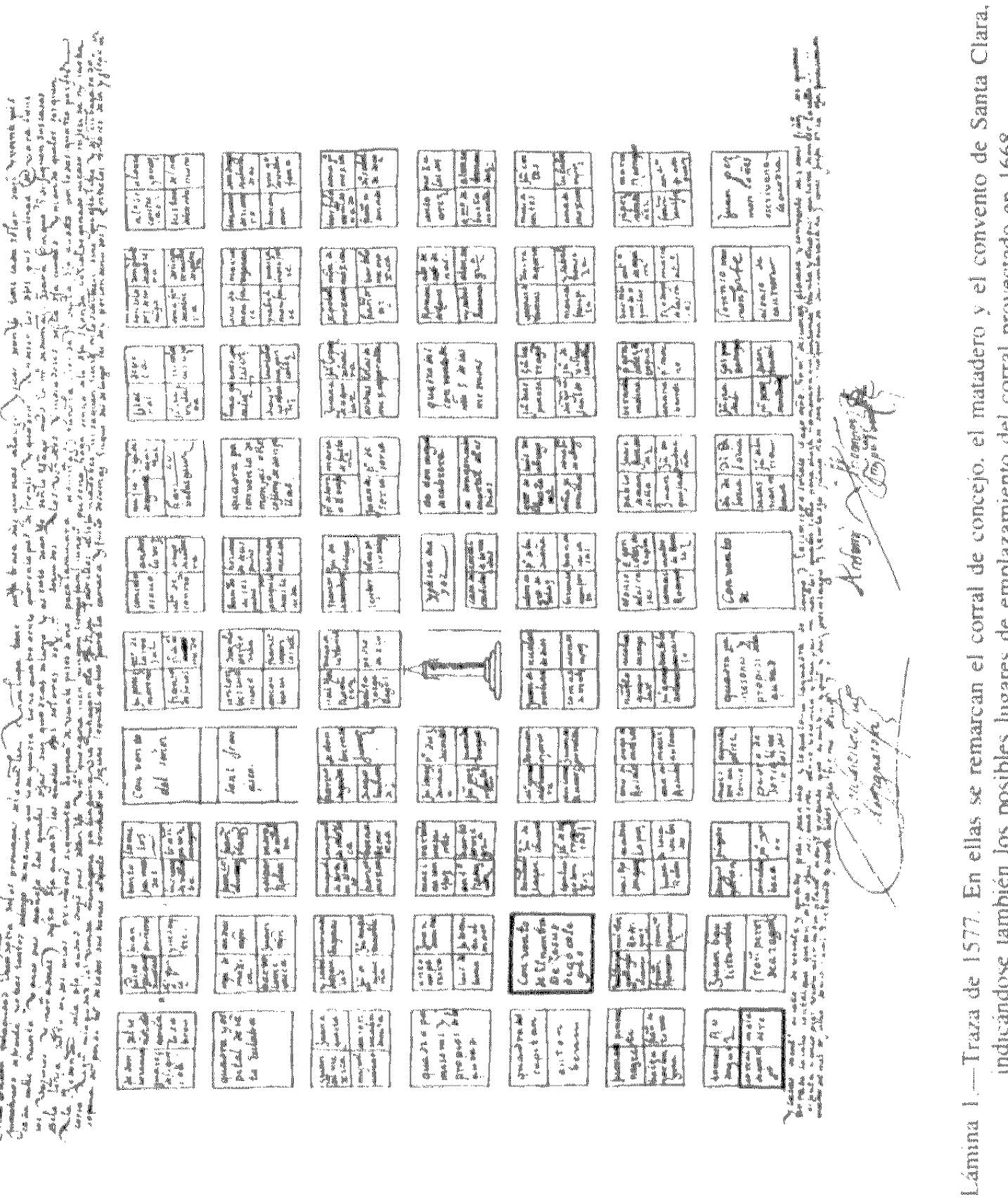




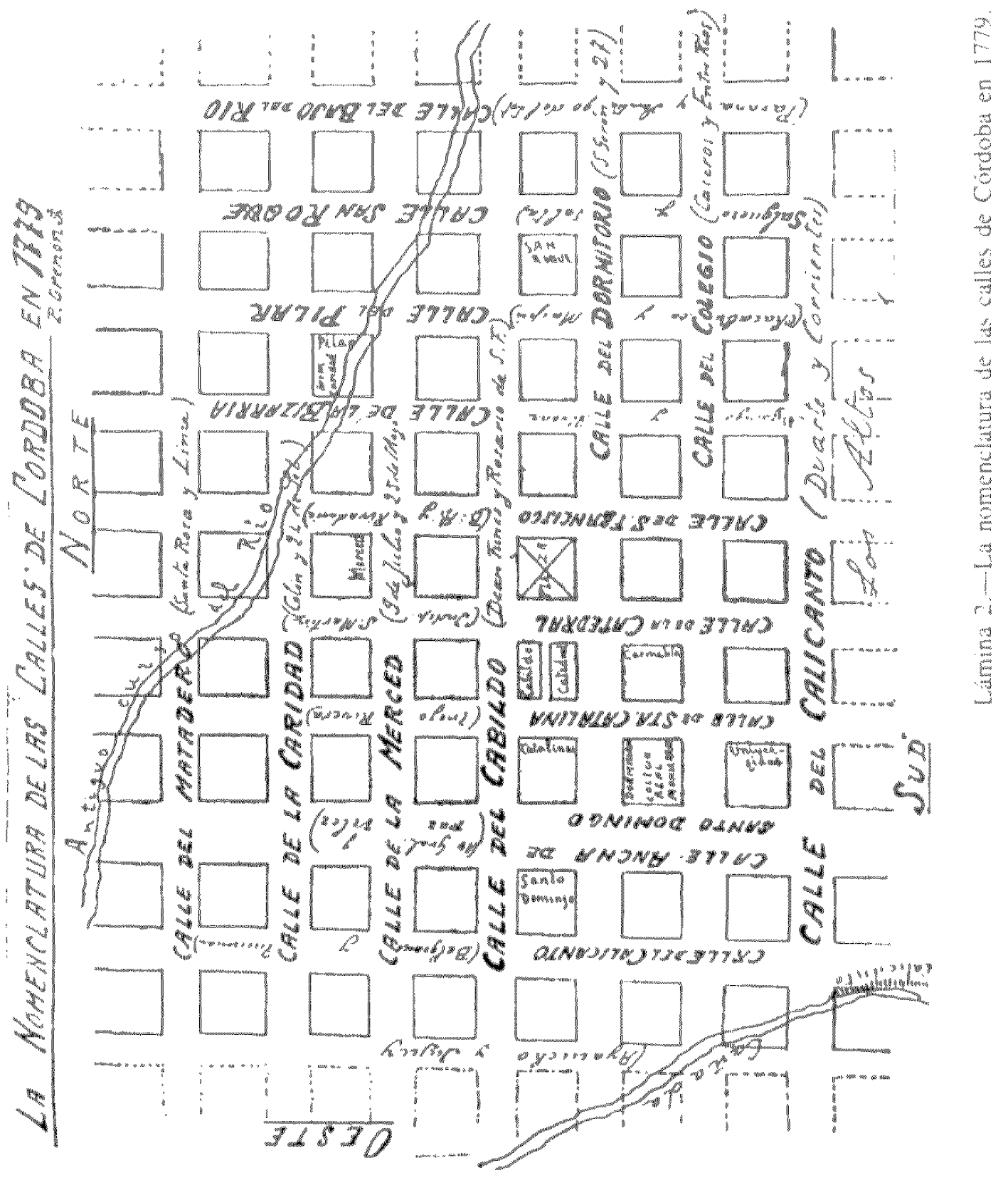




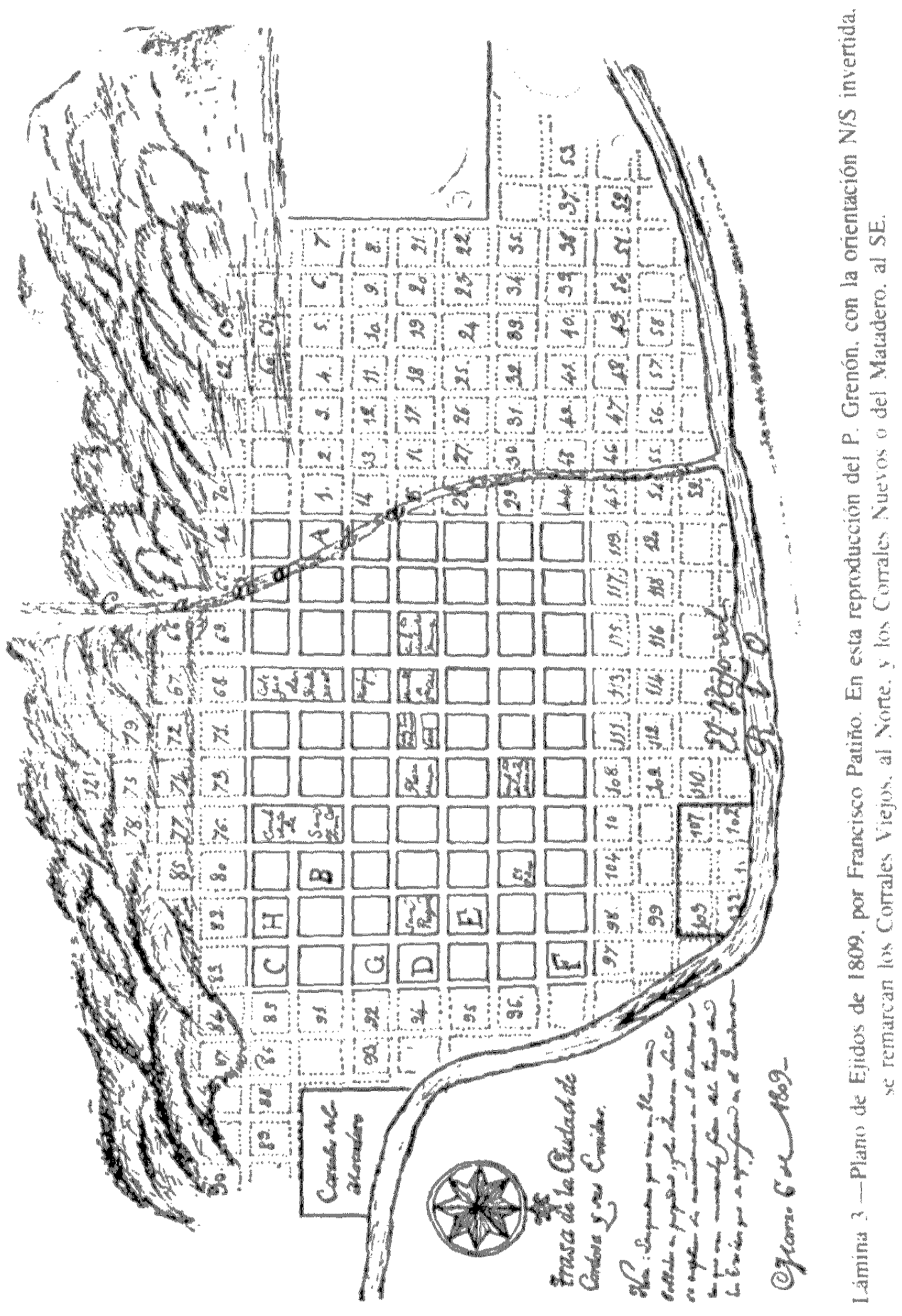




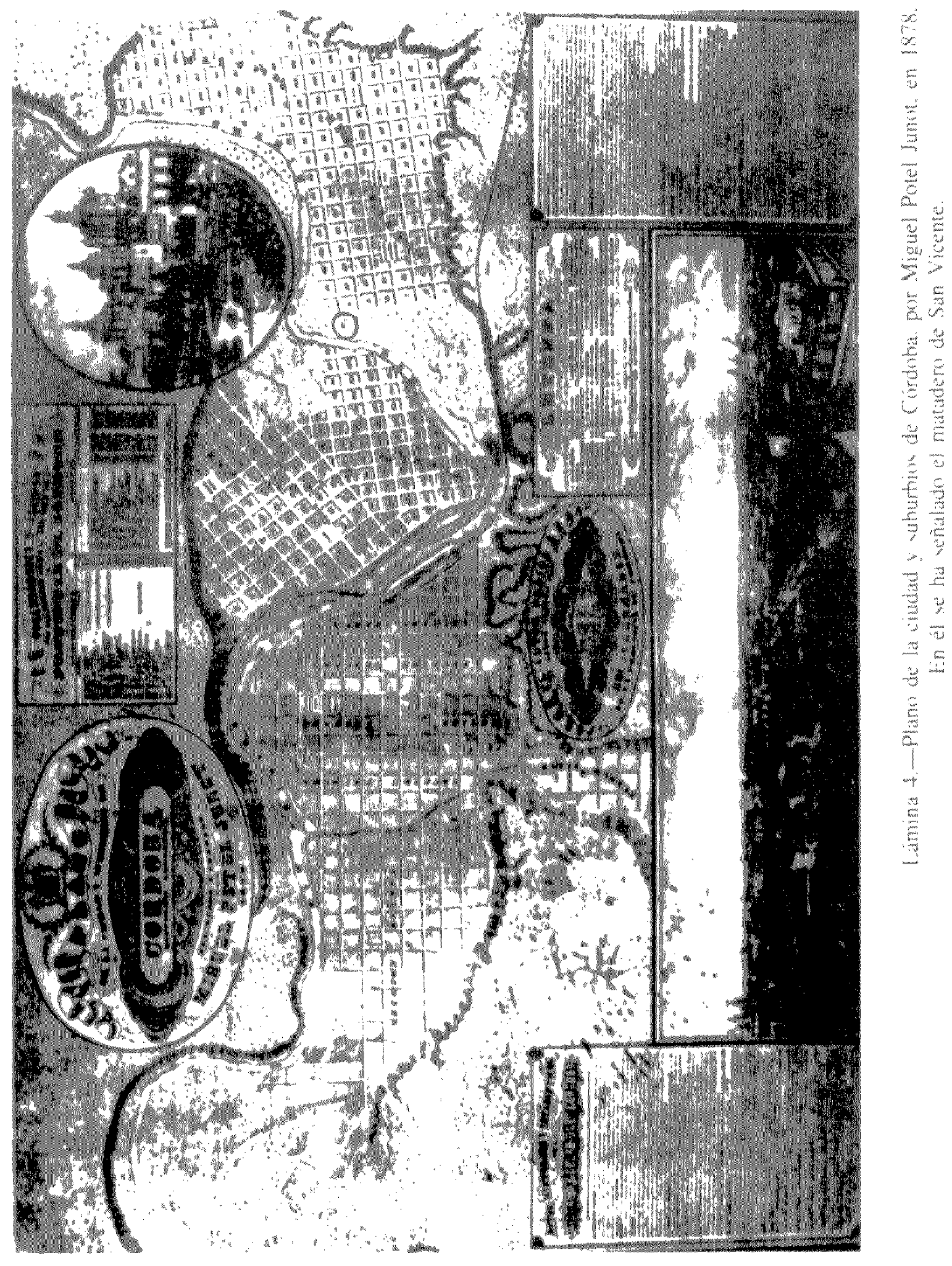




\section{Apéndice documental *}

[f. 135r.] "Instrucción que forma el Procurador General para el manejo y Govierno del fiel executor y maiordomo de Corrales en el expendio de la came en la Plaza y demas anexo, y conserniente a los Acuerdos celebrados en veinte y nuebe de Noviembre veinte y dos de diciembre del anterior año de ochenta y cinco y nuebe de enero del presente en el que para este efecto se comisionó al dicho Procurador General por el Ilustre Cabildo de esta Capital.

1. Primeramente será de la precisa obligacion del maiordomo de Corrales que se halla nombrado, y en adelante fuere precise a los introductores de ganado que luego que lleguen pasen a ver a los Señores Alcaldes y que les presenten los comprobantes que trajeron que acrediten traerlo bien comprado, y si no lo trajeren siendo la persona sospechosa podran los Jueces hazer las diligencias que les pareciere a esclarezer lo combeniente a dar licencia para la venta que deberá preceder inescriptis o a continuacion del que presenten para el Govierno del maiordomo y que este cobre un real por cada noche hasta que berifique su venta por el todo de la Partida.

2..$^{\circ}$ Se deberan hacer dos tablillas largas en que asienten los nombres de los sugetos que se ocupan en matar para el abasto de la plaza y al fin de el nombre de cada sugeto un barreno con un cordobancito con su nudo, que la una sirba para el maiordomo y la otra para el fiel executor de suerte que todos los que por la tarde saquen res de los corrales [f. $135 \mathrm{v}$.] para matanza les vaia el maiordomo tirando los nudos de su tablilla que acredite dever ir al siguiente dia a la plaza con ella, y lo mismo lo que maten por la mañana para venderla a la tarde y quedar en poder del mayordomo la llave del Porton del Rodeo sin fiarla a nadie.

3. ${ }^{\circ}$ todas las noches debera mandar el fiel executor su tablilla a lo del mayordomo o este por andar a caballo que sera mas facil venir a lo del fiel executor con la suia a ponerlas acordes con los nudos fuera de todos aquellos que deberan ir al siguiente dia a la Plaza para que con ella en mano dicho fiel executor pueda pasar lista y si saliesen algunos sugetos con carne fuera de lo de la lista se proceda a la aberiguacion donde se mataron quien las hubiera traido o vendido con reconosimiento de los

* AHPC, Gobierno, año 1786, Caja 8, capr. 2, fs. 135r a 137r. 
cueros y si saliese ser hurtadas se procederá a la prision del Conductor y al castigo del comprador o compradores, y a proceder a la venta de las que fuesen, depositandose el importe para satisfaccion a su dueño procurando darle aviso al que fuese con arreglo a la marca o señal o a la confesion que hiciere el que las trajo si se cojiese, para por este medio evitar tan continuos latrocinios, y si fueren traidas y compradas se les aplique la correspondiente multa de seis pesos por no haverlas llebado a los Corrales del publico la que se debera aplicar a la renta de propios por ser a quien le resulta el perjuicio.

4. ${ }^{\circ}$ Deberá celarse por el fiel executor y maiordomo de Corrales [f. 136r.] no se menudee la carne fuera de la Plaza encargandoles este cuidado a los propios que la abastecen por redundar a su beneficio el que todo se venda en ella y al que se cojiere vendiendo fuera se le aplique la correspondiente pena porque de esta suerte pase todo por la vista del fiel executor y no se sacrifique al publico vendiendo caada arbitrariamente como se le antoija y proporcionandose excesibas ganancias que no son permitidas en alimento de primera necesidad.

5. Será tambien obligacion del maiordomo de Corrales avisar al fiel executor el precio a que se venden las reses en pie y de la calidad que son para poder arreglar la Plaza y servir al publico con equidad y Justicia proporcionandoles una correspondiente ganancia al que la vende pero todo baxo de los arreglos que separados a esta Intruccion hiran.

6. Los vecinos hacendados u otros que matasen reses para el gasto de su casa no se les embarazara con tal que lo haga en el matadero o fuera de la ciudad en su corralon si lo tienen traiendolas desgarretadas para que los escombros y desperdicios de la res no ensucien las calles, pero si lo berificasen fuera del matadero deberan dar parte al fiel executor y si la vendiesen haia de ser precisamente en la Plaza dandole parte al maiordomo.

7. El arreglo que va hecho con concepto a lo general y mayor parte del año en que se compran [f. 136v.] las reses a los precios que en el se expresan no deva de ninguna manera embarazar que en cierta estacion abunda demaciadamente este abasto y comprandose por mas baxo precio dan mas porciones que las que van designadas en él de suerte que llegan a dar a real la pierna, dos y medio el costillar, quatro el pecho y assi respectibamente valiendose del arbitrio de correr las calles con carretillas vendiendola con el nombre de Baratillo que no se les embaraza esta diligencia pero si deberan hacerla despues de estar en la Plaza y obteniendo Licencia del fiel executor para ello = Por quanto todo lo que es abasto y mantenimiento debe celar el fiel executor se venda con la combeniente orden reconosiendo su calidad y actual situacion para evitar el que se reparta a 
los vecinos alimentos que perjudiquen la salud publica como son las frutas berdes se deberá poner todo cuidado en que se vendan en sazon y tambien lo tendrá en que las arinas que se venden al publico sean buenas y no de las fetidas y podridas por lo novibo (sic) que son las de esta calidad, las que se deve prohibir su venta y arrojarla al rio, y para que pueda hacer como corresponde esta operacion sera bueno sean antes reconozidas por personas practicas, y declarandolas ésta por pasadas o podridas se deberan quemar o arrojar como va dicho deviendo ser del cuidado de los dueños antes de empezar a venderlas dar parte al fiel executor para que le conste donde la hai y puede recono [f. 137r.] zer su calidad, el modo como se vende en que medida y a que precio, en lo que pondrá su maior cuidado a fin de desterrar el abuso de que en tiempo que escasea este genero no solo lebantan el precio sino es que cerzenan en la medida, abuso que se tiene por mui pernicioso y perjudicial, y se hace indispensable su abolicion=

A los Señores Alcaldes ordinarios toca inmediatamente celar sobre el cumplimiento de lo que en esta Instruccion ba prevenido y hacer que los fieles executores cumplan exactamente con la obligación de sus oficios para lo que se les pondrá un tanto de ella en cada Juzgado con el fin de que se tenga presente y puedan facilmente imponerse en ella y otra al fiel executor y al maiordomo de los capítulos que ablan con el poniendo por cabeza de ella el arreglo que va separado de las reses siendo lo unico que le ha parecido al Procurador hacer presente a este Ilustre Cabildo en desempeño de su obligacion y arreglado a los citados acuerdos. Cordova y Enero diez y seis de mil setecientos ochenta y seis = Gaspar Salcedo.” 